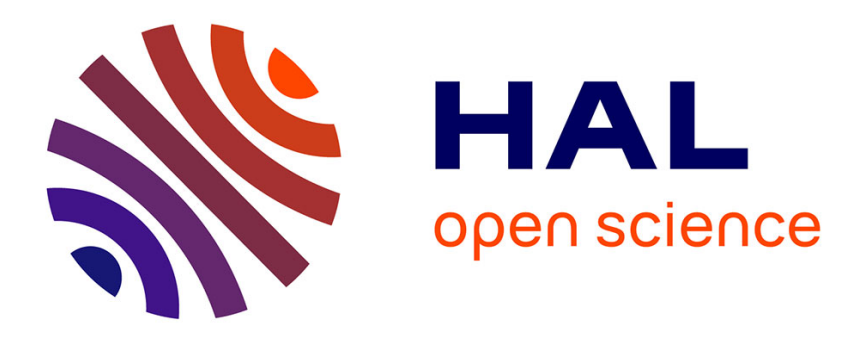

\title{
Correlated environmental impacts of wastewater management in a spatial context.
}

Sophie Legras

\section{To cite this version:}

Sophie Legras. Correlated environmental impacts of wastewater management in a spatial context.. Journées de Recherches en Sciences Sociales - JRSS-SFER 7e, 2013, Angers, France. 35 p. hal02805258

\section{HAL Id: hal-02805258 \\ https://hal.inrae.fr/hal-02805258}

Submitted on 6 Jun 2020

HAL is a multi-disciplinary open access archive for the deposit and dissemination of scientific research documents, whether they are published or not. The documents may come from teaching and research institutions in France or abroad, or from public or private research centers.
L'archive ouverte pluridisciplinaire HAL, est destinée au dépôt et à la diffusion de documents scientifiques de niveau recherche, publiés ou non, émanant des établissements d'enseignement et de recherche français ou étrangers, des laboratoires publics ou privés. 


\title{
Correlated environmental impacts of wastewater management in a spatial context
}

\author{
Sophie Legras ${ }^{\mathrm{a}}$ \\ ${ }^{a}$ INRA UMR 1041 CESAER, Dijon, FRANCE
}

Email address: sophie.legras@dijon.inra.fr (Sophie Legras) 


\begin{abstract}
We study the interplay between residential location choice, sprawl and water quality. We propose an urban economics model of a, first, monocentric, then, polycentric city with two different residential areas : sewer-serviced suburbia, with small residential lot size, and exurbia where wastewater management is individual and on-site and residential lots are larger to accomodate sanitary requirements. Sewer and septic are also characterized by different abatement efficiencies. Within this framework, where development is assumed contiguous, we analyse how wastewater management and commuting costs impact on residential location choice and consequently on sprawl and water quality. According to the abatement efficiency gap between sewer and septic technologies, improving water quality may be achieved at the expense of higher or lower sprawl. The extension to the polycentric setting allows introducing heterogeneities in wastewater and commuting costs that illustrate how independant policy makers may impact the sprawl and water quality of the entire metropolis.
\end{abstract}

Keywords. wastewater management, septic system, sewer system, residential water pollution, land use, commuting, polycentrism.

JEL codes : Q2, R1, R2, R3 


\section{Introduction}

An increasing share of the population lives in cities and their close hinterland. It is then crucial to understand how urban development, and the form this development takes, impact on the environment. Indeed, urban growth is associated with numerous damage to the environment : the transport of people and goods contributes to local air pollution and greenhouse gaz emissions (Kahn, 2006; Glaeser and Kahn, 2010; Hensher, 2002); the increase in impervious surfaces alters water ecosystems functioning (Lohse et al., 2008); land fragmentation is detrimental to biodiversity (Merenlender et al., 2009; Tannier et al., 2012); firms contribute to air pollution (Hwang and Mai, 2004); etc.

Furthermore, urban development can take different forms that don't impact these issues in the same way. Polycentric urban structures are becoming a prominent feature of the landscape worldwide, and the impacts of the decentralization of jobs and people within metropolises on the patterns of sprawl and greenhouse gaz emissions are not straightforward (Gaigné et al., 2012; Legras and Cavailhès, 2012). Beyond the organisation of productive activities, the nature of residential areas also matters in assessing the environmental impacts of urban growth. Heimlich and Anderson (2001) state that recent land development in the US takes two major forms : the continuous accretion of urban growth at the fringe of urban areas, in suburbia, and the multiplication of larget-lot housing beyond the urban fringe and in nonmetropolitan counties, exurbia. Suburban and exurban development represent two fundamentally different types of growth : the former relies on access to sewer and small residential lots $(<1$ acre), the latter is not bound to collective sewer and hence relies on septic systems and larger lot size (5 - 40 acres per unit) (Heimlich and Anderson, 2001; Newburn and Berck, 2011a). In a recent paper, Newburn and Berck (2011a) show the crucial role that wastewater technology choice plays on the type 
of development occuring at the urban fringe : additional costs entailed by municipal sewer extension may significantly reduce the reservation price of agricultural land in suburban use, while exurban development can occur immediately and entails only the onsite conversion costs. The bid rent of households with a preference for large lots may then exceed agricultural landowner's reservation price for future suburban use in what they coin an exurban "feasible zone" where development leapfrogs. This theoretical work establishes a strong link between wastewater technology choice and sprawl.

This link was indeed invoked by Maryland Governor O'Malley when advocating a "septic bill", adopted last year. This piece of legislation aims at limiting the development of new residential lots based on septic systems, especially in rural areas. Its justification is twofold : to reduce wastewater-related polluting inputs to the Chesapeake Bay and to curb urban sprawl. Relying on wastewater management as an indirect candidate to impact on sprawl appears appealing, given the seemingly lack of efficiency of direct instruments to limit sprawl (Newburn and Berck, 2011b; Harrison et al., 2012). An empirical examination by Newburn and Berck (2011b) shows that policies aimed at limiting urban growth are more effective to manage suburban rather than exurban development, with the potential adverse effect of encouraging development in exurbia, hence higher reliance on septic systems and a greater hold on land ressources. In the same vein, Harrison et al. (2012) show that septicbased development has increased significantly in the Baltimore region since the passage of Maryland's Priority Funding Area, a legislation aiming at focusing new development where there is existing infrastructure.

In this paper we analyse how wastewater management and commuting costs affect urban 
spread $^{1}$ and water quality to identify to what extent strategies undertaken to reduce one issue (e.g. altering the wastewater bill) may impact on the other one. We show that, depending on the relative abatement efficiencies of septic and sewer systems, strategies that improve water quality may either increase or decrease urban spread.

Key to the proposition of a joint management of water quality and sprawl is the assumption that septic systems are associated with a higher contribution to pollution load than collective sewer ones. Indeed, a number of papers have raised awareness on the detrimental impacts of poorly designed, sitted or maintained septic systems on water quality, especially groundwater (Arnade, 1999; Borchardt et al., 2003; Moore et al., 2003). Sewer systems also contribute to water pollution, and another range of papers assess the environmental performance of different types of collective sewer systems (Lassaux et al., 2003). There lacks studies that compare the impacts of sewer and septic systems on water quality; indeed they are not homogeneous in this respect : the former mainly impacts surface water while the latter has a more direct effect on groundwater; the effluents they generate are not homogeneous in type and quantity; septic failure is diffuse and develops over time without being noticed while sewer-related issues are more ponctual and quickly dealt with. Consequently, no a priori assumption is made regarding the efficiency gap in this paper, since it drives most of the results. Assessing which conditions on abatement apply to which context is an empirical matter outside the scope of this paper.

The paper is organised as follows. Section 2 presents the model of a monocentric city with sewer-serviced suburbia and septic-dependant exurbia. In section 3 we derive the spatial equilibrium, and analyse how the costs of wastewater management and commuting

\footnotetext{
${ }^{1}$ rather that sprawl, since we consider contiguous settlement both in suburbia and in exurbia.
} 
affect the population distribution over suburbia and exurbia. In section 4, we assess how these costs impact on two environmental variables associated with urban development : urban spread and water quality. Section 5 extends the analysis to a polycentric context and introduces heterogeneous commuting and wastewater costs. Section 6 concludes.

\section{The Model}

We first set our analysis within the standard framework of a monocentric city. It comprises a central business district (CBD), where all firms are located and do not consume land, and two types of residential rings : suburbia, where access to a sewer system is available and residential lot size $h_{s}$ is fixed and small, and exurbia, where there is no access to sewer : residential lot size $h_{e}$ is larger to accomodate the sanitary regulation on individual septic systems. Space has one dimension, $x \in \mathbb{R}$ and is symmetric to $x=0$ : without loss of generality, we will focus on the right hand side of the city where $x \geq 0$. The borders of the various areas are determined endogenously.

The city comprises a continuum of $N$ individuals, exogeneously determined since we consider a closed city. The agents consume a level $q(x)$ of an aggregate consumption commodity and an amount $h_{s}$ or $h_{e}$ of living space, depending if they reside in suburbia or exurbia, with $h_{s}<h_{e}$. They commute from their place of residence to the CBD at a unitary $\operatorname{cost} t>0$ per distance travelled. They generate water pollution $e(x)$ as a by-product of consumption. Wastewater infrastructure abate pollution to a different extent according to the system in use, sewer or septic. The amount of pollution emitted by a household located at $x$ is as follows :

$$
e(x)=\gamma_{i} q(x) \quad i \in\{s, e\}
$$

Abatement efficiencies are fixed but different according to the system in use. Wastewater 
systems are also characterized by different installation and monitoring costs. Septic only involves fixed costs $C_{e} \geq 0$ while sewer entails fixed costs and a variable component : $C_{s}(x)=a+b q(x), a, b \geq 0$. Wastewater infrastructure is assumed to be produced, installed and monitored by firms established outside the metropolis : refer to (Quaas, 2007) for a model with endogeneous infrastructure production.

On the production side, we assume that the aggregate composite commodity is produced in totality by the firms established in the $\mathrm{CBD}$, so that a firm profit function is given by :

$$
\Pi=p Q-\phi w
$$

with $p$ the price of the commodity, $Q$ the total production, $w$ the wage paid to workers and $\phi$ the number of labor units necessary to produce $Q$.

Hence, we consider identical agents which sort between suburbia and exurbia. Refer to (Newburn and Berck, 2011a) for the detailed analysis of how agricultural land is converted into either suburban use in the contiguity of the existing city limit, or exurban use in a "feasibility exurban zone" where households that highly value space induce leapfrog development for residential use with a septic system and a large lot size required for sanitary purposes. Here, we assume that exurban development is contiguous but keep the assumption that exurbia is associated with larger lot size and recourse to septic wastewater management, while in suburbia connection to sewer is guaranted and lot size is smaller. This allows us to quantify the environmental impacts of urban development, according to households' choice of residence in suburbia or exurbia, analytically. 


\section{Equilibrium monocentric structure}

To analyse the environmental impacts of wastewater management, we derive the equilibrium city structure in the case of a closed monocentric city. $N$ households maximise their utility, given their budget constraint, by chosing their composite commodity consumption level and their residential location; firms maximise profits. In equilibrium, all markets clear, and all households enjoy the same utility level.

We use a quasi-linear utility function : $U(q(x), h(x))=q(x)+v \ln h(x)$ with $v>0$. An agent's budget constraint depends on his location in suburbia (subscript $s$ ) or exurbia (subscript $e$ ) :

$$
\begin{gathered}
B C_{s}: \quad w=t x+R_{s}(x) h_{s}+p q_{s}(x)+a+b q_{s}(x) \\
B C_{e}: \quad w=t x+R_{e}(x) h_{e}+p q_{e}(x)+C_{e}
\end{gathered}
$$

where $R_{s}$ and $R_{e}$ are the bid rents functions. As agents settle continuously along the city line, we can express the values of the borders between suburbia and exurbia, $x_{s}$, and between exurbia and the agricultural hinterland, $x_{e}$, as follows, where $\beta, 0<\beta<1$, is the share of population in suburbia :

$$
x_{s}=N \beta h_{s} \quad \text { and } \quad x_{e}=x_{s}+N(1-\beta) h_{e}
$$

To derive the equilibrium repartition of population, we equate the equilibrium utilities of agents settled in suburbia and of those settled in exurbia. To do so, we derive the bid rent functions in each area by recognizing that, due to the fixed lot size assumption, there is equality of urban costs (commuting plus rent costs) within each area. Absentee landowners allocate land to the highest bidder. The opportunity rent is the agricultural rent $R_{a}$; it is set equal to zero for simplicity. The rent function is :

$$
R(x)=\max \left\{R_{s}(x), R_{e}(x), R_{a}\right\}
$$


where the bid rent functions are given by the following expressions :

$$
R_{s}(x)=\frac{t}{h_{s}}\left(x_{s}-x\right)+\frac{t}{h_{e}}\left(x_{e}-x_{s}\right) \quad \text { and } \quad R_{e}(x)=\frac{t}{h_{e}}\left(x_{e}-x\right)
$$

We plug these bid rent functions in the budget constraints to obtain the equilibrium consumption values in each zone ${ }^{2}$. Using these equilibrium values and the definitions of $x_{s}$ and $x_{e}$, we equate the equilibrium utility fonctions in exurbia and suburbia to derive the value of $\beta^{*}$, the equilibrium share of population in suburbia :

$$
\beta^{*}=1-\frac{p}{t\left(\hat{x}_{e}-\hat{x}_{s}\right)}\left[v \ln \frac{h_{e}}{h_{s}}-\frac{C_{e}-\left(a+b q_{e}^{*}\left(\hat{x}_{s}\right)\right.}{p+b}\right]
$$

where $\hat{x}_{e}=x_{e}(\beta=0)=N h_{e}$ is the eastern limit of a totally exurban city and $\hat{x}_{s}=x_{e}(\beta=$ 1) $=N h_{s}$ is the eastern limit of a totally suburban city. It can be shown that $0<\beta^{*}<1$ under conditions (C1) and (C2) described in Appendix 1.

Increasing the wage and the preference for larger lots, or reducing the transport cost tend to reduce the share of population settled in suburbia : by relaxing the budget constraint or increasing the utility from the consumption of a larger lot, it allows more agents to settle far from the CBD in the exurban area.

Wastewater management costs also have an impact on residential location choice (see Appendix 2) : any increase of the cost relative to septic tanks has the effect of increasing the share of population in suburbia, hence of decreasing the population in exurbia. This alters the borders of the city, moving $x_{s}$ to the east and $x_{e}$ to the west ( contrary, raising the costs of sewer increases settlement in exurbia.

\footnotetext{
${ }^{2}$ The equilibrium consumption values are $: q_{s}^{*}=\frac{w-a-t x_{s}-t\left(x_{e}-x_{s}\right) h_{s} / h_{e}}{p+b}$ and $q_{e}^{*}=\frac{w-C_{e}-t x_{e}}{p}$.
} 
Due to their effect of the equilibrium repartition of the fixed population between exurbia and suburbia, wastewater management costs ought to impact on the environmental performance of the metropolis, that we grasp through two variables : the total width of the city to assess the amount of natural or agricultural land converted to urban development and the aggregate residential pollution load.

\section{Land conversion and water quality in a monocentric city}

This section is devoted to the analysis of the impact of wastewater and commuting costs on the two environmental variables that we focus on in this paper : city width and residential pollution load. We chose to analyze these two costs since they are both policy bases of choice to manage the environmental impacts of urban development ${ }^{3}$.

The total width of the city is the location of the eastern border $x_{e}$ :

$$
S=x_{e}=N \beta^{*} h_{s}+N\left(1-\beta^{*}\right) h_{e}
$$

Residential pollution load is expressed as the sum over all agents of their pollution emissions, proportional to their consumption levels :

$$
E=\int_{x_{0}}^{x_{s}} \frac{\gamma_{s}}{h_{s}} q(x) d x+\int_{x_{s}}^{x_{e}} \frac{\gamma_{e}}{h_{e}} q(x) d x
$$

Proposition 1. Higher sewer costs, lower septic costs or higher commuting costs increase the spread of the city.

\footnotetext{
${ }^{3}$ Residential lot sizes also constitute an interesting policy basis, however it is difficult to sign analytically their environmental impacts.
} 
Proof. See Appendix 2.

Proposition 1 follows from the clear-cut impact of the cost parameters on $\beta^{*}$ : cheaper septic systems induce more agents in exurbia, where lot sizes are larger than in suburbia consequently more land is consumed by an agent choosing to live in exurbia compared to an agent settling in exurbia. Also, by tightening the budget constraints of all households, increasing commuting costs induce the city to shrink with more people settling in suburbia where the lot size is lower than in exurbia, and from where distances to work are smaller.

The impacts of wastewater-related and commuting costs on $S$ only channel through a change in the repartition of the population between suburbia and exurbia. In the case of $E$, changing the costs affects the repartition of population, which in turn affects the equilibrium consumption level, from where the pollution emission is generated. Consequently, for each parameter $a, b, C_{e}$ and $t$ there are three effects at play, so that the aggregate impact is not as clear-cut.

Proposition 2. Raising wastewater and commuting costs affects aggregate water pollution in three ways :

- a consumption effect that is always negative : increasing any type of cost decreases the level of consumption, hence the amount of pollution emitted, whatever the residential location;

- an exurbia effect stemming from the change of location of $x_{s}$ and $x_{e}$ : it is positive for $a$ and $b$, and negative for $C_{e}$ and $t$;

- a suburbia effect coming from the change of location of $x_{s}$ : it is of opposite sign as the exurbia effect. 
The aggregate impact depends on the abatement efficiency gap. When sewer is highly efficient or septic poorly efficient, any alteration of the costs that induce more agents to settle in suburbia result in a lower aggregate pollution load. When the opposite applies, reducing pollution entails inducing agents to settle in exurbia. The efficiency gap threshold depends on which cost is analyzed.

Proof. The equilibrium aggregate pollution load is given by the following expression :

$$
E^{*}=\frac{\gamma_{s}}{h_{s}} q_{s}^{*} x_{s}^{*}+\frac{\gamma_{e}}{h_{e}} q_{e}^{*}\left(x_{e}^{*}-x_{s}^{*}\right)
$$

where the equilibrium consumption levels and area borders depend on the cost parameters. Consequently, the impact of a cost parameter $j \in\left\{a, b, C_{e}, t\right\}$ can be broken down into the following terms :

$$
\frac{\partial E}{\partial j}=\frac{\gamma_{s} x_{s}^{*}}{h_{s}} \frac{\partial q_{s}^{*}}{\partial j}+\frac{\gamma_{e}\left(x_{e}^{*}-x_{s}^{*}\right)}{h_{e}} \frac{\partial q_{e}^{*}}{\partial j}+\frac{\gamma_{s} q_{s}^{*}}{h_{s}} \frac{\partial x_{s}^{*}}{\partial j}+\frac{\gamma_{e} q_{e}^{*}}{h_{e}}\left[\frac{\partial x_{e}^{*}}{\partial j}-\frac{\partial x_{s}^{*}}{\partial j}\right]
$$

The first two terms are negative for all cost parameters : it is the consumption effect that captures a decrease in consumption, hence in pollution emitted, when the budget constraint is tightened by the increase of a cost.

The third and fourth terms capture the impacts due to a change of repartition of the population between suburbia and exurbia. They are of opposite sign for each parameter : increasing the cost of any type of wastewater management induces more agents to settle in the area where the other system prevails; while increasing commuting costs unambiguously induces more agents to settle in suburbia.

The aggregate impacts can be signed after rearranging the terms (see Appendix 2). Raising the costs of sewer increases pollution load if the following applies : 


$$
\frac{\gamma_{s}}{\gamma_{e}} \leq \gamma_{a}=1-\frac{p v \ln \frac{h_{e}}{h_{s}}+t N\left(h_{e}-h_{s}\right)}{-p v \ln \frac{h_{e}}{h_{s}}+t N\left(h_{e}-h_{s}\right)+p q_{s}^{*}\left(\hat{x}_{s}\right)+\frac{p}{p+b}\left(C_{e}-a-b q_{e}^{*}\left(\hat{x}_{s}\right)\right)}
$$

In other words, if the ratio is low, with a very efficient sewer and poorly efficient septic, increasing the cost of sewer has the detrimental impact of increasing aggregate pollution load : while both consumption levels decrease, the transfert of population from suburbia to exurbia induce more use of a poorly efficient system, leading to a decrease in water quality. For a high ratio, increasing the cost of sewer induces less pollution emitted.

Raising the cost of septic increases the aggregate level of water pollution if the following applies :

$$
\frac{\gamma_{s}}{\gamma_{e}} \geq \gamma_{C_{e}}=1-\frac{v \ln \frac{h_{e}}{h_{s}}}{q_{s}^{*}\left(\hat{x}_{s}\right)}
$$

Under an efficient septic technology, and a less efficient sewer one, increasing septic costs may induce a higher equilibrium level of residential pollution. There needs to be a sufficient gap in depolluting efficiencies between the two technologies to ensure that water quality is improved when the cost of septic increases, reducing both consumption levels and the share of population settled in exurbia.

Raising commuting costs increases the aggregate level of water pollution if the following applies :

$$
\frac{\gamma_{s}}{\gamma_{e}} \geq \gamma_{t}=1+\frac{t^{2} N^{2} h_{s}^{2}\left(h_{e}-h_{s}\right)+(w-a)\left[(p+b)\left(v p \ln \frac{h_{e}}{h_{s}}-C_{e}\right)+w b+p a\right]}{t^{2} N^{2} h_{s}\left(p\left(h_{e}-h_{s}\right)+b h_{e}\right)-v p \ln \frac{h_{e}}{h_{s}}\left[(p+b)\left(v p \ln \frac{h_{e}}{h_{s}}-C_{e}\right)+w b+p a\right]}
$$

As for septic costs, since increasing transport costs induce more agents to settle in suburbia, it also leads to more pollution emitted if the abatement efficiency gap that septic is 
highly efficient as compared with sewer.

From Propositions 1 and 2 it appears that according to the abatement efficiency gap between sewer and septic technologies, the environmental objectives of reducing sprawl and residential pollution load, pursued by a policy maker, may appear conflicting.

Corollary 1. Implementing a transport tax/subsidy or a wastewater cost tax/subsidy is compatible with a reduction of both land conversion and residential pollution over only a range of abatement efficiency ratios. Outside of these ranges, the policy maker faces conflicting environmental objectives.

Proof. Proposition 1 establishes that the impact of wastewater and transport costs on land conversion are monotonous. Proposition 2 provides the threshold for each cost parameter that defines the sign of their impact on aggegate water quality. Consequently, it is easy to derive the following :

- decreasing $a$ or $b$ reduces both land conversion and pollution load for $\gamma_{s} / \gamma_{e} \in\left[0 . . \gamma_{a}\right]$; for $\gamma_{s} / \gamma_{e}>\gamma_{a}$, increasing $a$ or $b$ reduces pollution load at the expense of increased land conversion;

- increasing $C_{e}$ reduces both land conversion and pollution load for $\gamma_{s} / \gamma_{e} \in\left[0 . . \gamma_{C_{e}}\right]$; for $\gamma_{s} / \gamma_{e}>\gamma_{C_{e}}$, decreasing $C_{e}$ reduces pollution load at the expense of increased land conversion;

- increasing $t$ reduces both land conversion and pollution load for $\gamma_{s} / \gamma_{e} \in\left[0 . . \gamma_{t}\right]$; for $\gamma_{s} / \gamma_{e}>\gamma_{t}$, decreasing $t$ reduces pollution load at the expense of increased land conversion. 
Policy design being outside the scope of this paper, this Corollary only aims at pointing out some situations in which pursuing one environmental objective may be carried out at the expense of another one through the implementation of a unique instrument. Considering the environmental issues at stake in this paper, water quality often pertains to higher decision levels than the city, such as regional water institutions : environmental quality standards are defined and monitored along the whole water bodies or at their outset. Sprawl management is a more local issue. Consequently, an increase of the cost of septic to comply with tighter water quality regulation would have the added beneficial impact of decreasing sprawl for an abatement efficiency ratio below $\gamma_{C_{e}}$. Above this ratio, reducing water pollution load would necessitate a decrease in septic costs, and such a policy would entail more land conversion.

The next section extends the analysis of the environmental impacts of the urban form to the increasingly prominent feature of polycentric urban structures (Anas et al., 1998). This setting allows refining the analysis of potential interactions between policy instruments.

\section{Land conversion and water quality in a polycentric city}

In addition to the $\mathrm{CBD}$, the city comprises two sub-centers (SBD) where some jobs are provided and around which households can settle either in a suburbian ring or an exurban area. Besides the empirical interest in polycentric structures worldwide, they also constitute an interesting research topic in particular because their environmental performance is still not fully understood (Gaigné et al., 2012; Legras and Cavailhès, 2012). Given our focus on water quality in this paper, polycentricity allows introducing a certain range of heterogeneities that may enrich the analysis of the relationship between sprawl and residential pollution load. 
Consistent with the previous section, starting from a homogeneous case where all cost parameters are homogenous within the whole urban structure, we introduce heterogeneity on the following parameters : septic costs, sewer costs and commuting costs. This approach may constitute a first step in the analysis of strategic interactions between decisions makers within a urban structure, by providing the environmental consequences of a unilateral decision by the policy maker of the secondary urban area. As shown below, the consequences concern not only the area he is in charge of but also the whole urban structure. Note that no explicit strategic interaction is accounted for here; our approach is positive by treating the question of how urban spread and water quality would be affected over the whole structure, and within each primary and secondary urban area, by a decision taken in the secondary city.

\subsection{The Model}

The firms established in the SBD have the same production function as those established in the CBD; however they incur fixed communication costs $K>0$ to access some type of services that remain in the CBD preferably, such as banking, insurance, airports, etc. (Cavailhès et al., 2007). At the equilibrium, firms' profits are nul, so that the following relation links salary levels, where $w_{s}$ denotes the wage paid by SBD-established firms :

$$
w-w_{s}=\frac{K}{\phi}
$$

The wage difference between CBD and SBD based firms compensates for the communication costs borne by the latter. Lower wages in the SBD are consistent with lower urban costs incurred by households settled around the SBD.

As in the monocentric case, when choosing their residential locations agents decide whether to settle in suburbia or exurbia, leading to the equilibrium shares of agents in suburbia $\beta_{I}$ 
and $\beta_{I I}$, subscripts refering the the primary or secondary city. In this polycentric setting, they also have to choose between the primary and the secondary centers, resulting in a primary/secondary repartition share $\alpha$ : the higher $\alpha$, the lower the polycentric level of the metropolis. The resulting urban structure has the characteristics illlustrated in Figure 1 , where focus is given on the righ-hand side of the urban structure. The borders of the various areas are determined endogenously according to the equilibrium shares values.

\section{Figure 1 about here.}

Apart from the salary, all other parameters are assumed equal in the primary and the secondary urban areas; some of these assumptions are relaxed over the course of the section.

\subsection{Equilibrium urban structure and environmental impacts with homogeneous parame-} ters

The resolution strategy is the same as in the monocentric case, with the addition of spatial equilibrium conditions between the primary and the secondary areas that allow deriving the equilibrium polycentrism degree $\alpha$. To do so, besides the budget constraints established in section 4 for residents of the primary city, we also consider the following for secondary dwellers (refer to Appendix 3 for the expressions of the bid rents) :

$$
\begin{gathered}
B C_{s I I}: \quad w_{s}=t\left|x-x_{0 I I}\right|+R_{s I I}(x) h_{s}+p q_{s I I}(x)+a+b q_{s I I}(x) \\
B C_{e I I}: \quad w_{s}=t\left|x-x_{0 I I}\right|+R_{e I I}(x) h_{e}+p q_{e I I}(x)+C_{e}
\end{gathered}
$$

Equating the utility levels over the whole urban structure, we derive the following equilibrium population shares : 


$$
\begin{gathered}
\alpha^{*}=\frac{1}{3}\left[1+\frac{2\left(w-w_{s}\right)}{t h_{s} N}\right] \\
\beta_{I}^{*}=\frac{3 p h_{s} \Delta U_{1}}{\left(h_{e}-h_{s}\right)\left(2\left(w-w_{s}\right)+t h_{s} N\right.} \\
\beta_{I I}^{*}=\beta_{I}^{*}-\left(1-\beta_{I}^{*}\right) \frac{3\left(w-w_{s}\right)}{t h_{s} N-\left(w-w_{s}\right)}
\end{gathered}
$$

where $\Delta U_{I}=U_{I s}\left(\beta_{I}=1\right)-U_{I e}\left(\beta_{I}=0\right)$ is the is the utility difference between a totally suburbian city and a totally exurban city. To ensure that the share of population in suburbia is positive, this difference has to be positive, reflecting lower urban costs.

Due to our assumption of homogeneous wastewater management costs, they have no impact on the primary/secondary equilibrium repartition of the population. However, they impact on the suburban/exurban population shares around each BD : increasing sewer costs induce more settlement in exurbia; and vice versa.

Transport cost have an effect on all types of population shares : higher commuting costs lead to a more monocentric metropolis with more suburbanites. The mechanisms at stake are the same as in section 4 for the suburbia/exurbia residential choice. Due to the wage difference between the primary and the secondary centers, the budget constraint is less tightened by an increase in commuting costs for agents that settle around the CBD.

Compared to section 4, the environmental impact of the various costs that shape the urban form result from a residential choice that not only concerns living in suburbia or exurbia, but also living and working around the CBD or the SBD. Within the restricted framework of this paper, this choice only reflects the interplay between commuting, consumption, 
housing and wastewater management costs, some of which are assumed homogeneous over the metropolis or certains areas for the sake of readability of the results.

The total width of the city is now expressed as the location of the eastern border $x_{e I I}$ :

$$
S^{p}=x_{e I I}=N \alpha^{*}\left[\beta_{I}^{*} h_{s}+\left(1-\beta_{I}^{*}\right) h_{e}\right]+N\left(1-\alpha^{*}\right)\left[\beta_{I I}^{*} h_{s}+\left(1-\beta_{I I}^{*}\right) h_{e}\right]
$$

Proposition 3. Decreasing sewer costs, increasing septic costs, or increasing commuting costs, leads to less aggregate land conversion. Less land is converted around each business district, with less exurban conversion but more suburban conversion.

Proof. Refer to Appendix 2.

Given the clear impact of costs on population shares, it is not surprising that their impact on land conversion is also clear-cut. From proposition 3, we know that to achieve the objective of less aggregate land converted, the policy maker may have recourse to any of the following policies : taxing transport or septic costs, or subsidizing septic costs. In all cases, this induces less land converted around each business district. Furthermore, this gives rise to more land converted to suburbia, but less converted to exurbia, around each BD.

Residential pollution load is expressed as the sum over all agents of their pollution emissions, proportional to their consumption levels :

$$
E^{p}=\frac{\gamma_{s}}{h_{s}}\left[\int_{x_{0}}^{x_{s}} q_{s}(x) d x+2 \int_{x_{s I L}}^{x_{0 I I}} q_{s I I}(x) d x\right]+\frac{\gamma_{e}}{h_{e}}\left[\int_{x_{s}}^{x_{e}} q_{e}(x) d x++2 \int_{x_{e}}^{x_{s I I L}} q_{e I I}(x) d x\right]
$$

Proposition 4. Increasing septic management costs increases pollution load from suburban areas and reduces that from exurban areas. The impact on total, primary and 
secondary pollution loads depends on the abatement efficiency ratio between sewer and septic in a comparable manner as in the monocentric setting.

Proof. Refer to Appendix 3.

Since septic costs only affect the suburban/exurban population shares, and that they are a fixed component of the budget constraint, their impact in terms of water quality is quite straightforward in a polycentric setting. Indeed, they always increase the share of agents in suburbia, hence their total emission load, and reduce that of exurbia. The resulting effect depends on the abatement efficiencies of the wastewater technologies.

Proposition 5. Increasing sewer management costs always increases pollution load from suburban areas. Their impact on exurban pollution load depends on the consumption level gap between exurban and suburban households : when it is high, increasing the cost of sewer increases the pollution load from exurbia due to a transfert of population from suburbia; when it is low, an increase in the cost of sewer has the impact of reducing pollution load from exurbia due to a high reduction in consumption for all households. The impact on total pollution load, and on primary and secondary pollution loads, depends on the abatement efficiency ratio between sewer and septic.

Proof. Refer to Appendix 3.

Increasing $a$ always decreases the suburban pollution load since it decreases both the consumption level and the suburban population. A double effect is at play to explain the variation of $E_{e}$ with $a$ : a reduced consumption level of suburban households due to an increase of their wastewater bill which translates into less exurban consumption to comply with the spatial equilibrium; and a population transfert effect which increases the population emitting in exurbia. When the consumption levels gap between exurbia and suburbia is sufficiently high, increasing $a$ leads to a higher level of exurban pollution. 
Proposition 6. Increasing commuting costs always decreases pollution load from exurban areas. Their effect on suburban pollution load depends on the commuting costs level and how they affect both consumption and suburbia effects. The impact on total, primary and secondary pollution loads depends on the abatement efficiency ratio between sewer and septic.

Proof. Refer to Appendix 3.

Increasing $t$ always decreases the exurban pollution load since it decreases both the consumption level and the exurban population. A double effect is at play to explain the variation of $E_{s}$ with $t$ : a reduced consumption level and a population transfert effect which increases the population emitting in suburbia. The tradeoff between these effects explain the positive or negative effect on the suburban pollution load.

\subsection{Relaxing some homogeneity assumptions}

In this section we address the impact of introducing heterogeneity in some of the model's parameters, heterogeneity that could result from a policy maker's decision ${ }^{4}$. The parameters used for the simulations are stipulated in Appendix 4.

Let's consider first a change in the septic management costs in the SBD. The most recent French legislation on individual wastewater systems introduces mandatory controls by the municipal authorities in the areas which have been designated as not covered by a collective wastewater system. These mandatory controls have increased the cost of relying on septic. Furthermore, costs have proven to vary between municipalities. Figure 2 illustrates

\footnotetext{
${ }^{4}$ The results of this section are presented graphically; however, apart from the impact of heterogeneous commuting costs on pollution loads, the analytical derivations are available from the author upon request.
} 
the impact that an increase in secondary septic costs have on the urban structure, and on the width and pollution load of various areas : whole urban structure, primary and secondary urban areas, and total suburbia and exurbia.

\section{Figure 2 about here.}

First we can show that altering secondary septic costs has no impact on the primary city nor on the polycentrism degree. Consequently the environmental impacts of this cost alteration will only channel through a change of suburban/exurban repartition in the secondary city (see Section 4). Depending on the value of the abatement efficiency ratios, a policy maker willing to reduce the pollution load from its residents will either increase the septic cost, with the added benefit of less land converted, or decrease this cost at the expense of more land converted. Since the primary city is not affected, these results also apply to the whole urban structure.

\section{Figure 3 about here.}

Figure 3 illustrates how an alteration of sewer costs in the secondary suburban area affects the urban structure and its environmental performance. Contrary to the previous case, the whole city structure is affected : altering secondary sewer costs alters both suburban/exurban and primary/secondary population shares. Lowering this cost leads to a more polycentric structure, with more suburbanites around the SBD and less around the CBD. Increasing secondary sewer costs increases land conversion in around both cities towards more exurbia. According to the abatement efficiency ratio, this leads to either less, or more, pollution load in both cities. Consequently, a policy maker that would subsidize sewer costs to reduce the contribution of its city to water pollution (assuming that sewer 
is more efficient than septic), would also induce a decrease in pollution load from the primary city; furthermore, both city widths would be reduced.

\section{Figure 4 about here.}

Finally, Figure 4 shows the impacts of heterogeneous commuting costs. Increasing the per kilometer cost of commuting in the secondary city induce a more monocentric and suburban urban structure. While this effectively reduces the secondary city width, this also leads to a more spread primary city, which is not the focus of policy design ${ }^{5}$. Furthermore, both pollution loads are reduced, whatever the efficiency ratio.

\section{Concluding remarks}

In this paper, the link between water quality and urban spread is addressed through the analysis of household residential location and wastewater technology choice. We do so within the simplified framework of an urban economics model of a monocentric (and then polycentric) city, with two fixed, but different, residential lot sizes according to the location in suburbia or exurbia. This assumption of fixed but heterogenous lot sizes is a departure from standard urban economics models, where the lot size is either endogenously determined or unique over the whole urban structure. It allows the derivation of analytical results and still describes the stylized fact of decreasing lot size with distance from the city center (Legras and Cavailhès, 2012).

\footnotetext{
${ }^{5}$ Note that a general increase of commuting costs would have the same impact in terms of sprawl for both cities.
} 
We derive the impact of wastewater management and commuting costs on the shape of the city, namely the repartition of population between suburbia and exurbia, to grasp to which extent residential location choice is affected by the commuting and wastewater bills. Then we show how these costs also have the potential to alter the environmental performance of the city, with respect to urban spread and water quality : reducing city width doesn't necessarily imply a reduction in residential pollution load. Section 4 puts in perspective the crucial role of the abatement efficiency gap between sewer and septic technologies in the understanding of the link between urban spread and water quality.

The extension of the analysis to the case of a polycentric urban structure allows introducing heterogeneity with respect to some parameters. This approach constitutes a first step in the analysis of strategic interactions between decisions makers within a urban structure, by providing the environmental consequences of a unilateral decision by the policy maker of the secondary urban area. Once again, no explicit strategic interaction is accounted for here; we simply investigate how urban spread and water quality are affected over the whole structure, and within each primary and secondary urban area, by a decision taken in the secondary city.

This analysis rests on a series of simplifying assumptions that would need to be adressed in future research. First, we consider contiguous settlement in both suburbia, as is usually the case, and exurbia, which is less standard. This allows us to derive the environmental performance of the urban strutcure analytically. Second, sewer infrastructure is held externally : we don't analyse the provision of infrastructure per se and we don't introduce any heterogeneity within types of technology. Indeed, in the case of both sewer and septic systems, different technologies exist with different levels of performance regarding water pollution abatement. An extension of this work could endogeneize infrastructure provi- 
sion, in the vein of (Quaas, 2007), and allow for abatement efficiency to vary with the level of investment, especially in the case of sewer. This would introduce strategic interaction between policy makers in charge of, say, exurbia, suburbia, the primary or the secondary urban area. Finally, the depiction of the hydrological system at stake is absent from the analysis, since we only consider aggregate pollution to an undefined water body. The consideration of pstream/downstream interactions or surface/underground water links would enrich the analysis of the link between urban spread and water quality.

\section{References}

Anas, A., Arnott, R., Small, K. A., 1998. Urban Spatial Structure. Journal of Economic Literature 36, 1424-1464.

Arnade, L., 1999. Seasonal correlation of well contamination and septic tank distance. Ground Water 37 (6), 920-23.

Borchardt, M., Chyou, H., DeVries, E., Belongia, E., 2003. Septic system density and infectious diarrhea in a defined population of children. Environmental Health Perspectives $111(5), 742-48$.

Cavailhès, J., Gaigné, C., Tabuchi, T., Thisse, J.-F., 2007. Trade and the structure of cities. Journal of Urban Economics 62 (3), 383-404.

Gaigné, C., Riou, S., Thisse, J.-F., Sep. 2012. Are compact cities environmentally friendly? Journal of Urban Economics 72 (2-3), 123-136.

Glaeser, E. L., Kahn, M. E., May 2010. The greenness of cities: Carbon dioxide emissions and urban development. Journal of Urban Economics 67 (3), 404-418. 
Harrison, M., Stanwyck, E., Beckingham, B., Starry, O., Hanlon, B., Newcomer, J., 2012. Smart growth and the septic tank : wastewater treatment and growth management in the Baltimore region. Land Use Policy 29, 483-92.

Heimlich, R., Anderson, W., 2001. Development at the urban fringe and beyond : impacts on agriculture and rural land. Tech. Rep. Agricultural Economic Report No. 803, Economic Research Service, U.S. Department of Agriculture, Washington D.C.

Hensher, D. A., 2002. A Systematic Assessment of the Environmental Impacts of Transport Policy. Environmental and Resource Economics 22 (1-2), 185-217.

Hwang, H., Mai, C., 2004. The Effects of Pollution Taxes on Urban Areas with an Endogenous Plant Location. Environmental and Resource Economics 29 (1), 57-65.

Kahn, M., 2006. Green cities : urban growth and the environment. Brooking Institution Press, Washington D.C.

Lassaux, S., Renzoni, R., Germain, A., 2003. Life cycle assessment of water from the pumping station to the wastewater treatment plant. Int J LCA 12, 118-126.

Legras, S., Cavailhès, J., 2012. Urban form and sustainable development. Working Paper Working paper CESAER 2012/5, CESAER.

Lohse, K.A and, N. D., Opperman, J., Merenlender, A., 2008. Forecasting relative impacts of land use on anadromous fish habitat to guide conservation planning. Ecological Applications 18, 467-82.

Merenlender, A., Reed, S., Heise, K., 2009. Exurban development influences woodland bird composition. Landscape and urban planning 92, 255-63. 
Moore, J., Schindler, D., Scheuerell, M., Smith, D., Frodge, J., 2003. Lake eutrophication at the urban fringe, USA. AMBIO 32 (1), 13-18.

Newburn, D., Berck, P., Nov. 2011a. Exurban development. Journal of Environmental Economics and Management 62 (3), 323-336.

Newburn, D. A., Berck, P., 2011b. Growth Management Policies for Exurban and Suburban Development : Theory and an Application to Sonoma County, California. Agricultural and Resource Economics Review 3 (December), 375-392.

Quaas, M. F., 2007. Pollution-reducing infrastructure and urban environmental policy. Environment and Development Economics 12 (2), 213-34.

Tannier, C., Foltête, J.-C., Girardet, X., Mar. 2012. Assessing the capacity of different urban forms to preserve the connectivity of ecological habitats. Landscape and Urban Planning 105 (1-2), 128-139.

\section{Appendix 1 : conditions for $0<\beta^{*}<1$}

The denominator of $\beta^{*}$ is positive. The positivity of its numerator is ensured by the following condition :

$$
v\left[\ln \left(h_{e}\right)-\ln \left(h_{s}\right)\right]<\frac{C_{e}-\left(a+b q_{e}^{*}\left(\hat{x}_{s}\right)\right)}{p+b}+\frac{t\left(\hat{x}_{e}-\hat{x}_{s}\right)}{p}
$$

The RHS of the above inequality is composed of two terms : the difference in wastewater management costs and the difference in commuting costs between the eastern limits of a totally exurban and a totally suburban city. In other words, $\beta^{*}$ is positive, hence there is a suburban area in the city, if the difference in utility derived from the lot size between exurbia and suburbia does not compensate for the difference in commuting costs 
and wastewater management costs.

To ensure $\beta^{*}<1$, the following condition must be met :

$$
v\left[\ln \left(h_{e}\right)-\ln \left(h_{s}\right)\right]>\frac{1}{(p+b)}\left[C_{e}-\left(a+b q_{e}^{*}\left(\hat{x}_{s}\right)\right)\right]
$$

where $\hat{x}_{s}=x_{s}(\beta=1)=N h_{s}$ is the eastern limit of a totally suburban city. The RHS of the expression represents the difference of utility due to a higher lot size in exurbia; the LHS represents the difference in wastewater management cost between exurbia and the eastern limit of a totally suburbian city. In other words, $\beta^{*}$ is less than unity, i.e. there is an exurbian zone in the city, when the gain in utility from a higher lot size more than compensates for the difference in wastewater management costs.

\section{Appendix 2 : impacts of the various cost parameters in the monocentric case}

The impacts of the cost parameters are derived as follows :

$$
\begin{gathered}
\frac{\partial \beta^{*}}{\partial a}=\frac{-p}{(b+p) t N\left(h_{e}-h_{s}\right)}<0 \quad, \quad \frac{\partial \beta^{*}}{\partial C_{e}}=\frac{1}{t N\left(h_{e}-h_{s}\right)}>0 \quad, \quad \frac{\partial \beta^{*}}{\partial b}=\frac{-q_{s}^{*}\left(\hat{x}_{s}\right)}{(b+p) t N\left(h_{e}-h_{s}\right)}<0 \\
\text { and } \frac{\partial \beta^{*}}{\partial t}=\frac{w-C_{e}-p q_{e}^{*}-\frac{p}{p+b} t N h_{s}}{t^{2} N\left(h_{e}-h_{s}\right)}>0
\end{gathered}
$$

The latter expression is positive by the exurban budget constraint and the fact that $\frac{p}{p+b} t N h_{s}<$ $t N h_{e}$.

The derivation of the impact of the cost parameters on $S$ is as follows :

$$
\frac{\partial S}{\partial a}=\frac{p}{t(p+b)}>0, \quad \frac{\partial S}{\partial C_{e}}=-\frac{1}{t}<0, \quad \frac{\partial S}{\partial b}=\frac{p q_{s}^{*}\left(\hat{x}_{s}\right)}{t(p+b)}>0
$$




$$
\text { and } \frac{\partial S}{\partial t}=-N\left(h_{e}-h_{s}\right) \frac{\partial \beta^{*}}{\partial t}<0
$$

The impacts of the cost parameters on the aggregate pollution load are as follows :

$$
\begin{aligned}
& \frac{\partial E}{\partial b}=q_{s}\left(\hat{x}_{s}\right) \frac{\partial E}{\partial a} \text { and } \frac{\partial E}{\partial a}=\gamma_{e} p(p+b)\left[-2 v \ln \frac{h_{e}}{h_{s}}+q_{s}^{*}\left(\hat{x}_{s}\right)+\frac{C_{e}-a-b q_{e}^{*}\left(\hat{x}_{s}\right)}{p+b}\right] \\
& +\gamma_{s}(p+b)\left[p v \ln \frac{h_{e}}{h_{s}}-\operatorname{tn}\left(h_{e}-h_{s}\right)-p q_{s}^{*}\left(\hat{x}_{s}\right)-\frac{p}{p+b}\left(C_{e}-a-b q_{e}^{*}\left(\hat{x}_{s}\right)\right)\right]
\end{aligned}
$$

The term attached to $\gamma_{s}$ is negative by compliance with (C1).

$$
\begin{gathered}
\frac{\partial E}{\partial C e}=\frac{1}{\left(h_{e}-h_{s}\right) t}\left[\gamma_{e} v \ln \frac{h_{e}}{h_{s}}-\left(\gamma_{e}-\gamma_{s}\right) q_{s}^{*}\left(\hat{x}_{s}\right)\right] \\
\frac{\partial E}{\partial t} t^{2}\left(h_{e}-h_{s}\right)(p+b)^{2}=\gamma_{s} M_{1}+\gamma_{e} M_{2} \\
M_{1}=(w-a)\left[(p+b)\left(v p \ln \frac{h_{e}}{h_{s}}-C_{e}\right)+p a+w b\right]+t^{2} N^{2}\left(p h_{s}\left(h_{s}-h_{e}\right)-h_{e}(p+b)\right) \\
M_{2}=(w-a)\left[(p-b)(p+b) v p \ln \frac{h_{e}}{h_{s}}-C_{e}(p+b)+p a+w b\right]+v(p+b)^{2} \ln \frac{h_{e}}{h_{s}}\left(C_{e}-a-v p \ln \frac{h_{e}}{h_{s}}\right)-b\left(t h_{s} N\right)^{2}
\end{gathered}
$$

\section{Appendix 3 : polycentric setting}

Given the budget constraint equation defined in section 5, we obtain the bid rent functions by equating the urban costs within each area of the city :

$$
\begin{gathered}
R_{s I}(x)=\frac{t}{h_{s}}\left(x_{s}-x\right)+\frac{t}{h_{e}}\left(x_{e}-x_{s}\right) \\
R_{e I}(x)=\frac{t}{h_{e}}\left(x_{e}-x\right)
\end{gathered}
$$




$$
\begin{gathered}
R_{\text {sILL }}(x)=\frac{t}{h_{s}}\left(x-x_{s I I}\right)+\frac{t}{h_{e}}\left(x_{s I I}-x_{e}\right) \\
R_{e I I L}(x)=\frac{t}{h_{e}}\left(x-x_{e}\right)
\end{gathered}
$$

The various area limits are given by the following expressions :

$$
\begin{gathered}
x_{s}=N \alpha \beta_{I} h_{s} ; \quad x_{e}=x_{s}+N \alpha\left(1-\beta_{I}\right) h_{e} ; \quad x_{s I L L}=x e+\frac{1}{2} N(1-\alpha)\left(1-\beta_{I I}\right) h_{e} \\
x_{\text {oII }}=x_{s I I L}+\frac{1}{2} N(1-\alpha) \beta_{I I} h_{s}
\end{gathered}
$$

Wastewater management and commuting costs affect land consumption in the following manner :

$$
\begin{gathered}
\frac{\partial S^{p}}{\partial a}=\frac{3 p}{t(p+b)}>0, \quad \frac{\partial S^{p}}{\partial C_{e}}=-\frac{3}{t}<0, \quad \frac{\partial S^{p}}{\partial b}=\frac{3 p q_{s}^{*}\left(\hat{x}_{s}\right)}{t(p+b)}>0 \\
\text { and } \frac{\partial S^{p}}{\partial t}=-\frac{b\left(w_{c}+2 w_{s}\right)+3 p a-3 C_{e}(p+b)+3 v p(p+b) \ln \frac{h_{e}}{h_{s}}}{t(p+b)^{2}}<0
\end{gathered}
$$

Proposition 4 is derived from the following results :

$$
\begin{gathered}
\frac{\partial E^{p}}{\partial C_{e}}=\frac{\partial E_{s}^{p}}{\partial C_{e}}+\frac{\partial E_{e}^{p}}{\partial C_{e}} \quad, \quad \frac{\partial E_{1}^{p}}{\partial C_{e}}=\frac{1}{3} \frac{\partial E^{p}}{\partial C_{e}} \quad \text { and } \quad \frac{\partial E_{2}^{p}}{\partial C_{e}}=\frac{2}{3} \frac{\partial E^{p}}{\partial C_{e}} \\
\frac{\partial E_{s}^{p}}{\partial C_{e}}=\gamma_{s} \frac{w_{c}+2 w_{s}-3 a-t N h_{s}}{t\left(h_{e}-h_{s}\right)(p+b)}>0 \\
\frac{\partial E_{e}^{p}}{\partial C_{e}}=-\gamma_{e} \frac{w_{c}+2 w_{s}-3 a-t N h_{s}-3 p v(p+b) \ln \frac{h_{e}}{h_{s}}}{t\left(h_{e}-h_{s}\right)(p+b)}<0
\end{gathered}
$$

Proposition 5 stems from the following results : 


$$
\begin{gathered}
\frac{\partial E^{p}}{\partial a}=\frac{\partial E_{s}^{p}}{\partial a}+\frac{\partial E_{e}^{p}}{\partial a} \quad, \quad \frac{\partial E_{1}^{p}}{\partial a}=\frac{1}{3} \frac{\partial E^{p}}{\partial a}-\frac{2}{3} \frac{\gamma_{s}\left(w-w_{s}\right)}{h_{s} t(p+b)} \quad \text { and } \quad \frac{\partial E_{2}^{p}}{\partial a}=\frac{2}{3} \frac{\partial E^{p}}{\partial a}+\frac{2}{3} \frac{\gamma_{s}\left(w-w_{s}\right)}{h_{s} t(p+b)} \\
\frac{\partial E_{s}^{p}}{\partial a}=\frac{\gamma_{s}}{h_{s}}\left[q_{s}^{*} \frac{\partial\left(x_{s}+2 x_{0 I I}-2 x_{s I L}\right)}{\partial a}+\left(x_{s}+2 x_{0 I I}-2 x_{s I I L}\right) \frac{\partial q_{s}^{*}}{\partial a}\right]<0 \\
\frac{\partial E_{e}^{p}}{\partial a}=\gamma_{e} \frac{3\left(p q_{e}^{*}-b q_{s}^{*}+v p \ln \frac{h_{e}}{h_{s}}-C_{e}+a\right)}{t\left(h_{e}-h_{s}\right)(p+b)}
\end{gathered}
$$

Proposition 6 is derived from the following results :

$$
\begin{gathered}
\frac{\partial E^{p}}{\partial t}=\frac{\partial E_{s}^{p}}{\partial t}+\frac{\partial E_{e}^{p}}{\partial t} \quad, \quad \frac{\partial E_{1}^{p}}{\partial t}=\frac{1}{3} \frac{\partial E^{p}}{\partial t}-\frac{2}{9} \frac{\gamma_{s}\left(w-w_{s}\right)\left(w+2 w_{s}-3 a\right)}{h_{s} t^{2}(p+b)} \\
\text { and } \frac{\partial E_{2}^{p}}{\partial t}=\frac{1}{3} \frac{\partial E^{p}}{\partial t}+\frac{2}{9} \frac{\gamma_{s}\left(w-w_{s}\right)\left(w+2 w_{s}-3 a\right)}{h_{s} t^{2}(p+b)} \\
\frac{\partial E_{s}^{p}}{\partial t}=\frac{\gamma_{s}}{h_{s}}\left[q_{s}^{*} \frac{\partial\left(x_{s}+2 x_{0 I I}-2 x_{s I I L}\right)}{\partial t}+\left(x_{s}+2 x_{0 I I}-2 x_{s I I L}\right) \frac{\partial q_{s}^{*}}{\partial t}\right] \\
\frac{\partial E_{e}^{p}}{\partial t}=\frac{\gamma_{e}}{h_{e}}\left[q_{e}^{*} \frac{\partial\left(-x_{e}-x_{s}+2 x_{s I I L}\right)}{\partial t}+\left(-x_{e}-x_{s}+2 x_{s I I L}\right) \frac{\partial q_{e}^{*}}{\partial t}\right]<0
\end{gathered}
$$

\section{Appendix 4 : parameters used in the simulations}

For all the simulations, a common set of parameters is used : $h_{e}=1.2, h_{s}=1, w=1, w_{s}=$ $0.5, N=1, p=1, v=11, b=0.1$. Then, to test for the consequence of heterogeneities, the following parameters are used : 


\begin{tabular}{cccccc}
\hline & $C_{e}$ & $a$ & $t$ & $\gamma_{s} / \gamma_{e}$ high & $\gamma_{s} / \gamma_{e}$ low \\
\hline Fig 1 & $C_{e I}=0.3$ & 0.1 & 1 & $\gamma_{s}=0.8, \gamma_{e}=0.1$ & $\gamma_{s}=0.1, \gamma_{e}=0.8$ \\
Fig 2 & 0.3 & $a_{I}=0.1$ & $t_{I}=1$ & $\gamma_{s}=0.8, \gamma_{e}=0.1$ & $\gamma_{s}=0.01, \gamma_{e}=0.8$ \\
Fig 3 & 0.3 & 0.1 & 1 & $\gamma_{s}=0.9, \gamma_{e}=0.3$ & $\gamma_{s}=0.1, \gamma_{e}=0.8$ \\
\hline
\end{tabular}

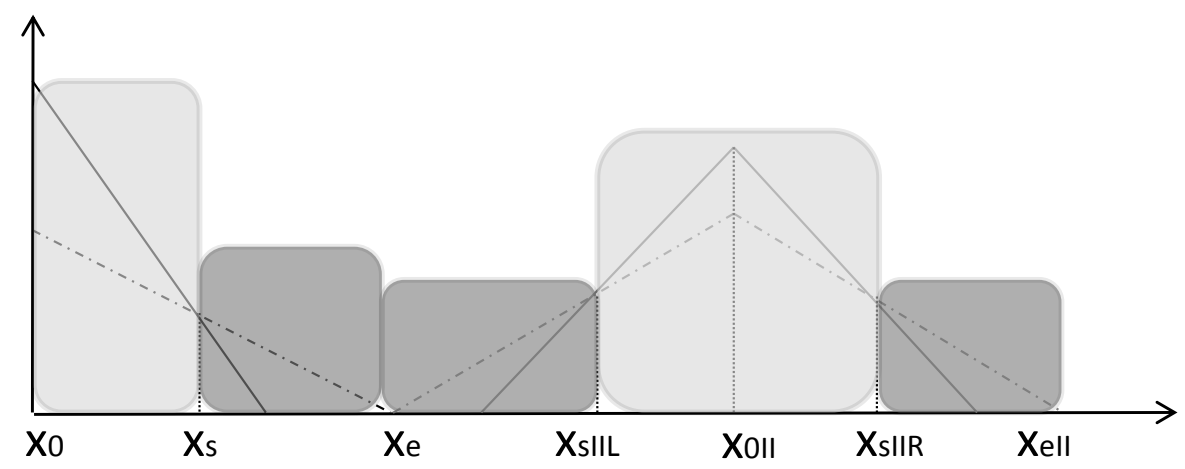

Figure 1: Polycentric urban structure. Light grey shaded area : suburbia, dark grey shaded area : exurbia. Straight and dotted lines are, respectively, suburban and exurban bid rent functions. 

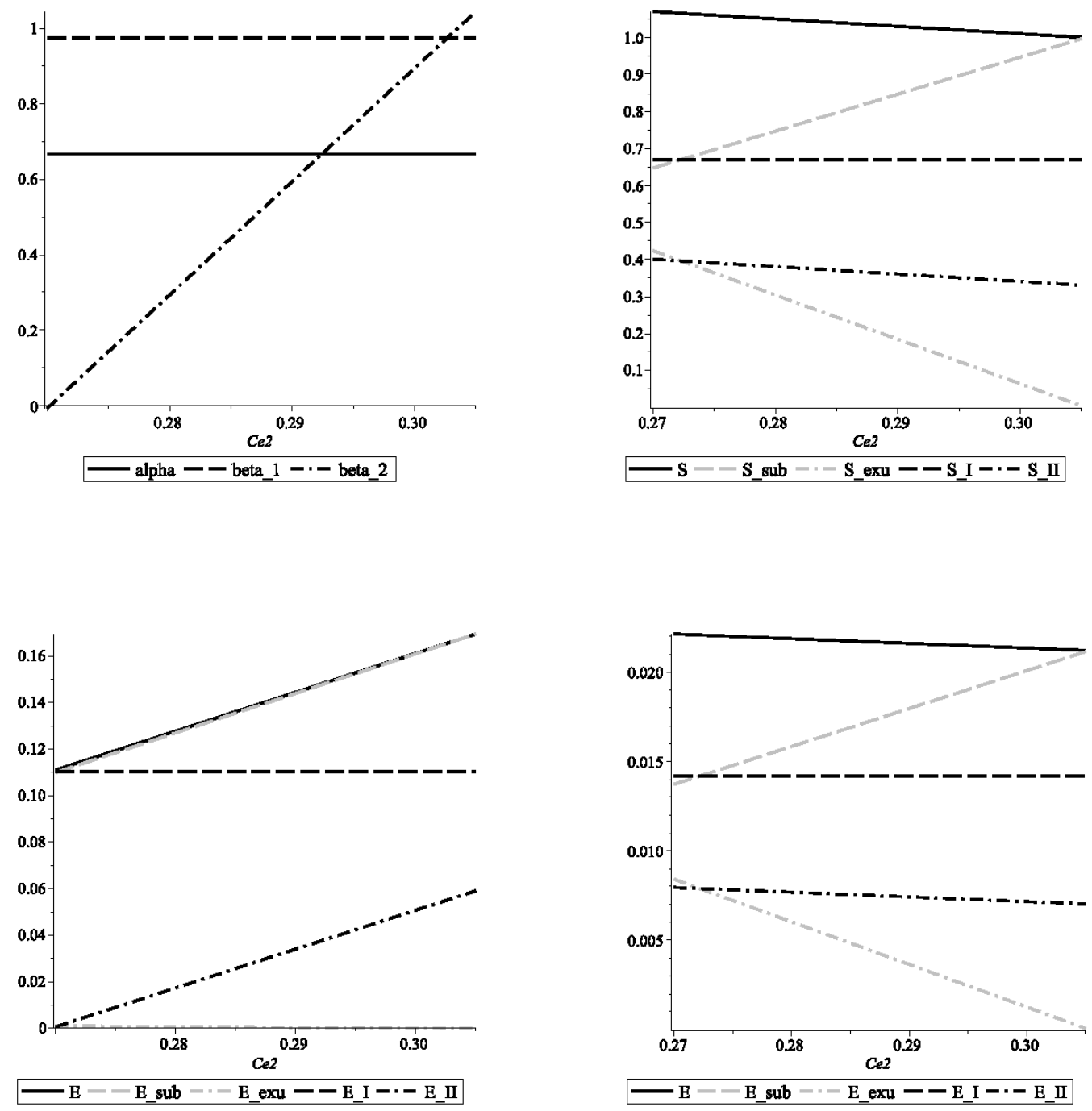

Figure 2: Impact of heterogeneity of septic costs. Clockwise from top left corner : urban structure, urban spread, pollution load with high $\gamma_{s} / \gamma_{e}$, pollution load with low $\gamma_{s} / \gamma_{e}$. 

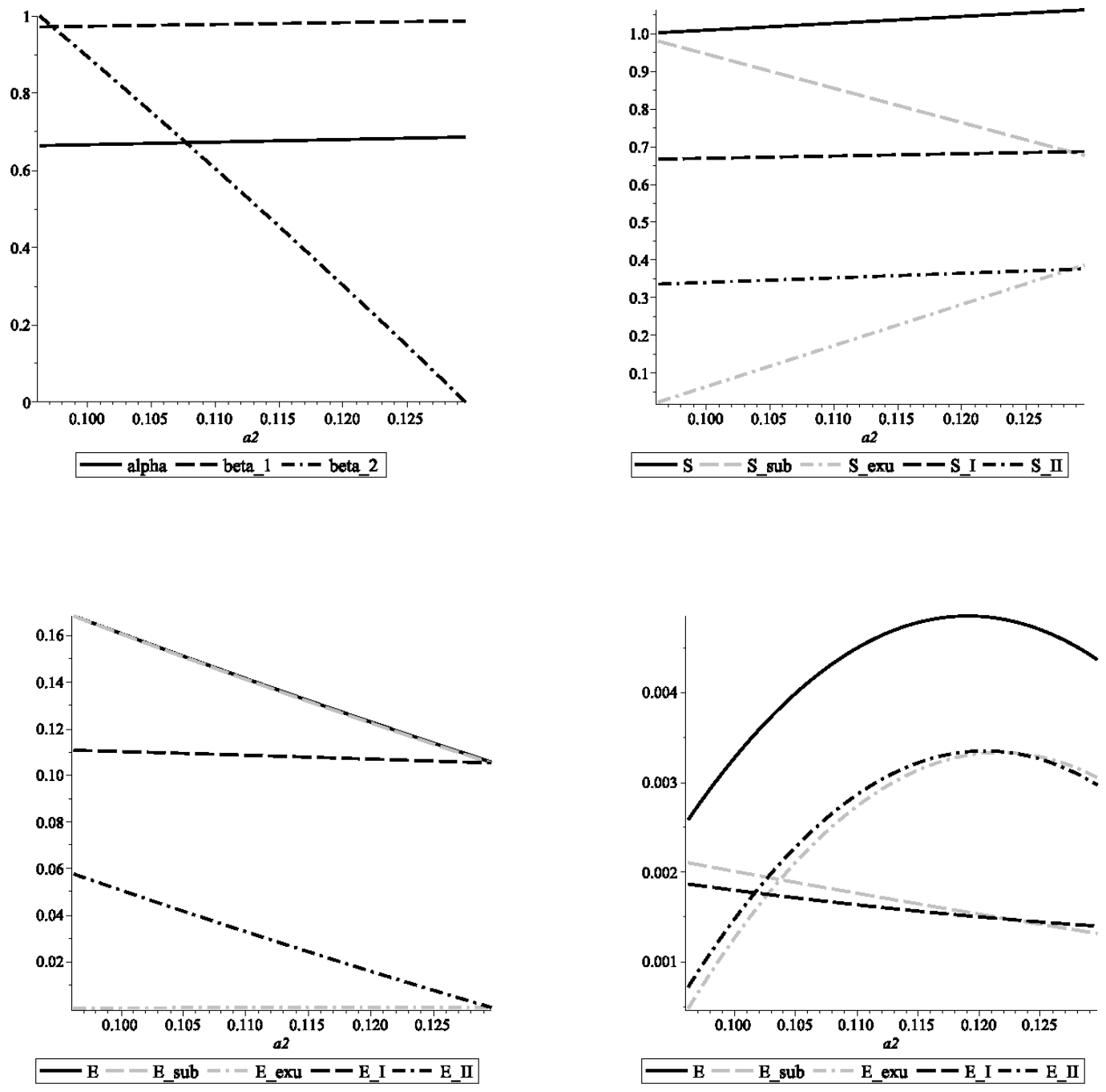

Figure 3: Impact of heterogeneity of sewer costs. Clockwise from top left corner : urban structure, urban spread, pollution load with high $\gamma_{s} / \gamma_{e}$, pollution load with low $\gamma_{s} / \gamma_{e}$. 

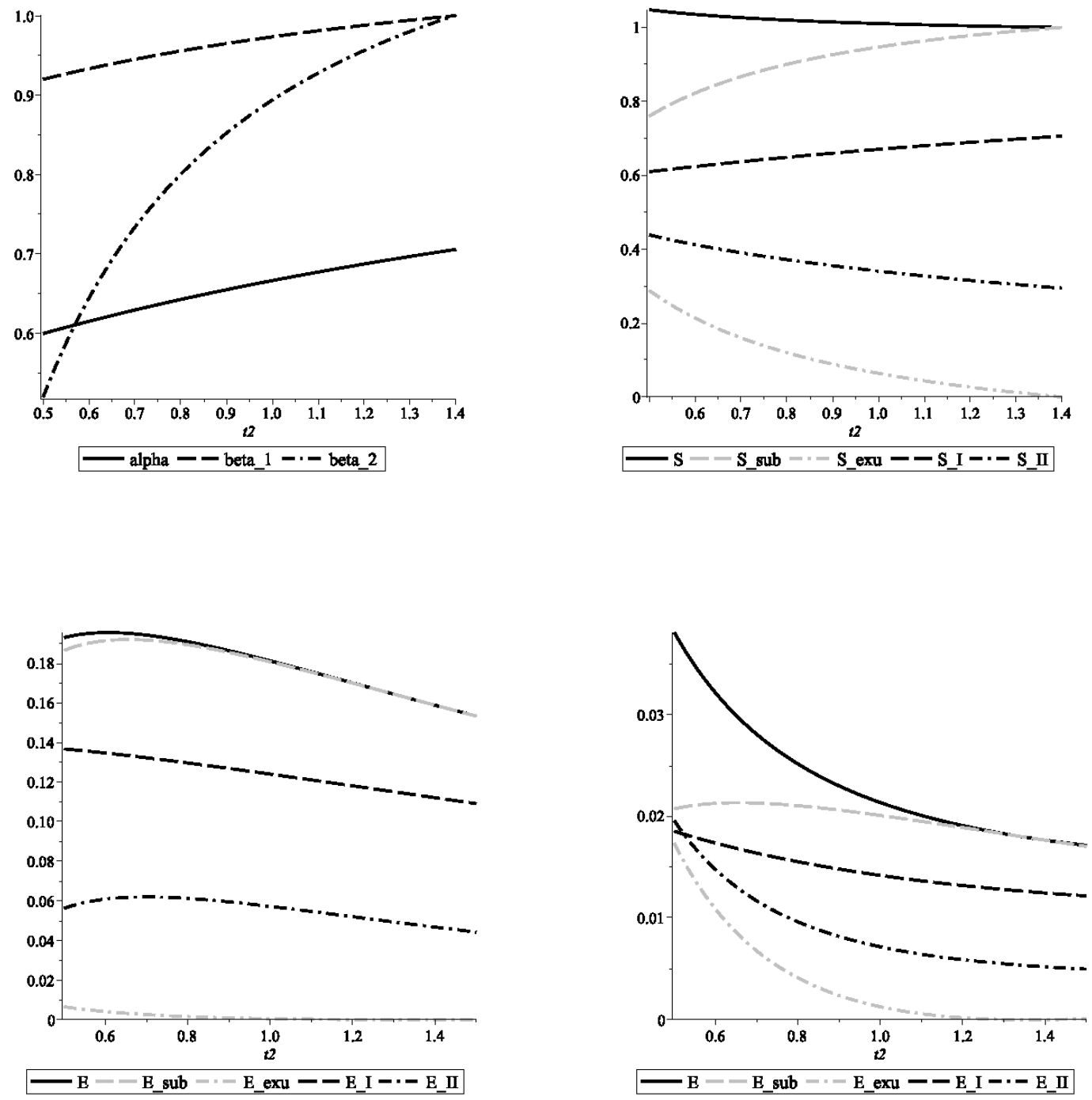

Figure 4: Impact of heterogeneity of commuting costs. Clockwise from top left corner : urban structure, urban spread, pollution load with high $\gamma_{s} / \gamma_{e}$, pollution load with low $\gamma_{s} / \gamma_{e}$. 